\title{
UMA SOLUÇÃO PARA O SISTEMA BRASILEIRO DE COLETA DE DADOS AMBIENTAIS BASEADA EM NANOSSATÉLITES
}

\author{
K. I. P. de M. QUEIROZ ${ }^{* 1}$, S. M. DIAS ${ }^{1}$, J. M. L. DUARTE ${ }^{2}$, M. J. M. de CARVALHO ${ }^{2}$ \\ ${ }^{1}$ Universidade Federal do Rio Grande do Norte, ${ }^{2}$ Instituto Nacional de Pesquisas Espaciais \\ kurios@laci.ufrn.br ${ }^{*}$
}

Submetido 27/10/2017 - Aceito 19/12/2018

DOI: $10.15628 /$ holos.2018.6307

\section{RESUMO}

Neste artigo, será apresentado o projeto CONASAT (Constelação de Nanossatélites Ambientais) desenvolvido pelo INPE (Instituto Nacional de Pesquisas Espaciais), em parceria com a AEB (Agência Espacial Brasileira) e a UFRN (Universidade Federal do Rio Grande do Norte). O objetivo principal desse projeto é apresentar uma solução de baixo custo para o Sistema Brasileiro de Coleta de Dados Ambientais (SBCDA), baseada em uma constelação de nanossatélites, com massa entre $1 \mathrm{~kg}$ a $10 \mathrm{~kg}$, usando tecnologias emergentes nos ramos da eletrônica e das telecomunicações. Adicionalmente, será apresentada uma visão geral dos principais produtos tecnológicos do projeto CONASAT: o Receptor/Decodificador para SBCDA e ARGOS, chamado de Environmental Data Collector (EDC), e o software do Subsistema de Determinação e Controle de Atitude (SDCA). O primeiro é responsável por receber e decodificar os dados oriundos das Plataformas de Coleta de Dados Ambientais (PCDs), enquanto que o segundo é responsável por determinar a orientação atual do satélite, denominada de atitude, e por direcionar os equipamentos a bordo (antenas e/ou câmeras) em posições específicas da terra ou do espaço. Por fim, algumas conclusões e considerações finais sobre o projeto CONASAT serão apresentadas.

PALAVRAS-CHAVE: Nanossatélites, CONASAT, EDC, Receptor/Decodificador para Nanossatélites, Controle de Atitude, Sistema Brasileiro de Coleta de Dados Ambientais.

\section{A SOLUTION FOR THE BRAZILIAN ENVIRONMENTAL DATA COLLECTING SYSTEM BASED ON NANOSATELLITES}

\begin{abstract}
In this paper, the CONASAT (Environmental Nanosatellite Constellation) project will be presented. This initiative has been developed by the INPE (National Institute For Space Research) in partnership with the AEB (Brazilian Space Agency) and UFRN (Federal University of Rio Grande do Norte). The principal objective of this project is to design a low cost solution for the Brazilian Environmental Data Collecting System (SBCDA) based on a nanosatellite (weighing between $1 \mathrm{~kg}$ and $10 \mathrm{~kg}$ ) constellation and using emerging technologies from the electronic and telecommunication fields. Moreover, a general view of
\end{abstract}

the main CONASAT products will be presented: the Receiver/Decoder system, which is compatible with the SBCDA and the ARGOS system, called Environmental Data Collector (EDC); and the software developed for the nanosatellite Attitude Determination and Control System (ADCS). The former is used to receive and decode the data from the PCDs (Data Collecting Platforms) and the second is used to change the satellite orientation with respect to a specified reference frame according to the operational necessities. Finally, some conclusions and comments about the CONASAT project will be

presented. 


\section{INTRODUÇão}

Os primeiros satélites projetados e fabricados no Brasil foram desenvolvidos pelo INPE (Instituto Nacional de Pesquisas Espaciais) e tinham como objetivo a coleta de dados ambientais. Nomeados de SCD1 e SCD2 (Satélite de Coleta de Dados 1 e 2), foram lançados na década de 90 com uma previsão de vida útil em torno de 1 e 2 anos, respectivamente. Entretanto, superando todas as expectativas de operação, ainda continuam ativos em 2018, alimentando o Sistema Integrado de Dados Ambientais (SINDA). Tal sistema é responsável pelo processamento, armazenamento e disseminação, para instituições governamentais e do setor privado, dos dados coletados remotamente por Plataformas de Coleta de Dados Ambientais (PCDs). Diversas aplicações e pesquisas em diferentes temáticas, tais como o monitoramento de bacias hidrológicas, previsão meteorológica, o estudo da química da atmosfera, a avaliação do potencial de energias renováveis, e o rastreio de animais silvestres são realizadas com base nos dados fornecidos pelo SINDA.

Historicamente, além dos satélites SCD-1 e SCD-2, podemos destacar outras iniciativas no desenvolvimento de satélites pelo INPE, como os projetos SACI (Satélites de Aplicações Científicas) e CBERS (China Brazil Earth Resources Satellites). Os satélites do projeto SACI não chegaram a operar de fato. O SACl-1, lançado como carga secundária no lançador do CBERS-1 (primeiro satélite do convênio Brasil-China), não se comunicou com as estações em solo, apesar de ter entrado em sua órbita nominal. Já o SACI-2, em virtude de uma falha no Veículo Lançador Terrestre (VLS) brasileiro, foi destruído logo no seu lançamento. Quanto ao projeto CBERS, foram lançados cinco satélites: CBERS-1, CBERS-2, CBERS-2B, CBERS-3 e CBERS-4. Apesar de obterem sucesso nas suas missões, os três primeiros satélites não estão mais operantes em 2018 (http://www.cbers.inpe.br/). O lançamento do CBERS-3 fracassou em 2013 e o CBERS-4 continua em operação e atende ao Sistema Brasileiro de Coleta de Dados Ambientais (SBCDA). É interessante ressaltar que o satélite CBERS-1 apresentou dificuldades operacionais somente 4 anos após o seu lançamento, apesar de uma estimativa de operação em torno de 2 anos (Winter \& Prado, 2007).

Em virtude da demanda regional para o monitoramento espacial ambiental do semiárido e do atlântico tropical, o INPE pretende desenvolver a próxima geração de satélites para o monitoramento ambiental. Essa próxima geração fará uso da larga experiência do INPE na concepção, desenvolvimento e fabricação de satélites, em conjunto com a sua estreita relação com as universidades brasileiras. Particularmente, podemos destacar a parceria entre a unidade do Centro Regional do INPE, localizada em Natal (INPE/CRN), e a Universidade Federal do Rio Grande do Norte (UFRN), que resultou nos últimos anos no projeto denominado de CONASAT (Constelação de Nanossatélites Ambientais). O objetivo principal desse projeto é apresentar uma solução de baixo custo para o SBCDA, baseada em uma constelação de nanossatélites, com massa entre $1 \mathrm{~kg}$ a $10 \mathrm{~kg}$, usando tecnologias emergentes nos ramos da eletrônica e das telecomunicações. 
Neste artigo, será apresentado uma visão geral do projeto CONASAT e de seus principais produtos tecnológicos: o Receptor/Decodificador para o SBCDA e para o sistema ARGOS ${ }^{1}$, chamado de Environmental Data Collector (EDC), e o software do Subsistema de Determinação e Controle de Atitude (SDCA). O primeiro é responsável por receber e decodificar os dados oriundos das PCDs, enquanto que o segundo é responsável por determinar a orientação atual do satélite, denominada de atitude, e por direcionar os equipamentos a bordo (antenas e/ou câmeras) em posições específicas da terra ou do espaço.

Além do projeto CONASAT, existem outras iniciativas brasileiras no desenvolvimento de nanossatélites. Dentre elas, podemos destacar os projetos NANOSATC, AESP, SERPENS e ITASAT (Ereno, 2014). São integrantes dessas iniciativas, diferentes unidades do INPE, como a unidade de Santa Maria e São José dos Campos, diversas universidades brasileiras, como a UFSM (Universidade Federal de Santa Maria), o ITA (Instituto Tecnológico de Aeronáutica) e a UNB (Universidade de Brasília), assim como a Agência Espacial Brasileira (AEB). Até o momento (dezembro de 2018), já foram lançados 4 nanossatélites, mas somente 3 (NANOSATC-BR1, SERPENS-1 e ITASAT-1) entraram em operação. O AESP-14, que foi colocado no espaço a partir da estação espacial internacional em fevereiro de 2015, permaneceu inoperante possivelmente devido a uma falha no sistema de abertura de uma de suas antenas. No dia 3 de dezembro de 2018, o ITASAT-1 foi lançado com uso do veículo lançador Falcon 9 da empresa americana SpaceX. Partindo da Base de Vandenberg, na Califórnia, Estados Unidos, o lançador transportou 64 satélites de 34 organizações e 17 países diferentes, incluindo EUA, Austrália, Finlândia, Reino Unido, Brasil e índia.

\section{O SISTEMA BRASILEIRO DE COLETA DE DADOS (SBCD) E O PROJETO CONASAT}

A missão dos satélites do Sistema Brasileiro de Coleta de Dados Ambientais (SBCDA) é retransmitir os dados oriundos de estações remotas (PCDs), localizadas em qualquer ponto do território nacional, e de plataformas marítimas, para estações receptoras em solo brasileiro. Cada PCD, após coletar informações ambientais (como temperatura e umidade, por exemplo), realiza uma transmissão de forma omnidirecional na banda de frequência UHF (Ultra High Frequency), em aproximadamente $401 \mathrm{MHz}$. Os satélites de coleta de dados (segmento espacial), ao passar na região de visibilidade da plataforma, recebem os sinais emitidos das PCDs e realizam imediatamente a retransmissão para as estações em terra do INPE (segmento solo) onde os dados capturados pelas PCDs são recuperados. Por fim, os dados são disponibilizados às diversas entidades e pessoas interessadas pelo SINDA.

Atualmente, o segmento espacial do SBCDA é composto pelos satélites SCD-1 e SCD-2, de órbita equatorial inclinada, que garante uma alta taxa de passagem sobre o território nacional, e pelo satélite CBERS-4, de órbita heliossíncrona. Essa última, garante que o satélite cruze ascendendo a linha do equador sempre no mesmo horário e local. Isto resulta em condições iguais de iluminação entre passagens diferentes, característica desejável para a aplicação principal dos satélites da família CBERS, que é o imageamento da Terra. No entanto, por ser uma

${ }^{1}$ ARGOS é um sistema franco-americano de coleta de dados ambientais. Para mais detalhes, acesse o endereço 
órbita quase polar, a órbita heliossíncrona não é favorável para a aplicação de coleta de dados no território brasileiro, por implicar em uma menor taxa de passagem sobre o território nacional.

Quanto ao segmento solo, existem duas estações receptoras, uma em Cuiabá/MT e outra em Alcântara/MA. É interessante ressaltar que o centro de controle da missão (nesse caso, o SINDA), que funcionava antes em Cachoeira Paulista/SP, foi transferido em meados de 2010 para a unidade do INPE em Natal/RN.

Em virtude da importância do SBCDA, um dos principais objetivos do projeto CONASAT é a renovação e expansão de sua constelação de satélites. A ideia é garantir a continuidade do SBCDA, além de possibilitar a ampliação da capacidade e do alcance geográfico do serviço de coleta de dados ambientais, com a inclusão do Oceano Atlântico Tropical. Para tal, o INPE escolheu um padrão de nanossatélites conhecido como Cubesat (http://www.cubesat.org). As principais vantagens dessa tecnologia correspondem ao seu baixo custo (aproximadamente 0,7 milhão de US\$ para cada satélite do CONASAT), em relação aos projetos anteriores do INPE (ver Tabela 1), e a sua rapidez no desenvolvimento/operação. Hoje já é possível adquirir pela internet um conjunto de hardware e software pronto para operar.

Tabela 1: Custo de alguns satélites construídos pelo INPE no período de 1961 a 2007 (Sousa, 2007).

\begin{tabular}{c|c|c}
\hline Satélite(s) & $\begin{array}{c}\text { Construção } \\
\text { (em milhões de US\$) }\end{array}$ & $\begin{array}{c}\text { Lançamento } \\
\text { (em milhões de US\$) }\end{array}$ \\
\hline SCD-1 & 20,0 & 13,5 \\
SCD-2 & 11,0 & 15,0 \\
SACI-1 & 4,6 & - \\
SACI-2 & 1,0 & - \\
CBERS-1 e 2 & 71,9 & 18,2 \\
\hline
\end{tabular}

O CubeSat é um padrão para a estrutura mecânica externa de satélites e para o lançador desses, que foi criado para reduzir o custo das missões espaciais. Esse padrão, que estabelece um formato de um cubo com arestas de $10 \mathrm{~cm}$ (padrão $1 \mathrm{U}$ ) para os satélites, foi pensado para missões com fins acadêmicos e/ou de treinamento. Entretanto, com a extensão desse conceito para formatos $2 \mathrm{U}, 3 \mathrm{U}, 6 \mathrm{U}$ e $8 \mathrm{U}$ (montados como se fossem brinquedos do tipo LEGO), o que era apenas uma forma de incentivar os estudantes americanos, unindo teoria e prática, passou a ser uma alternativa atrativa para diversos fins, como apresentado na Figura 1. 


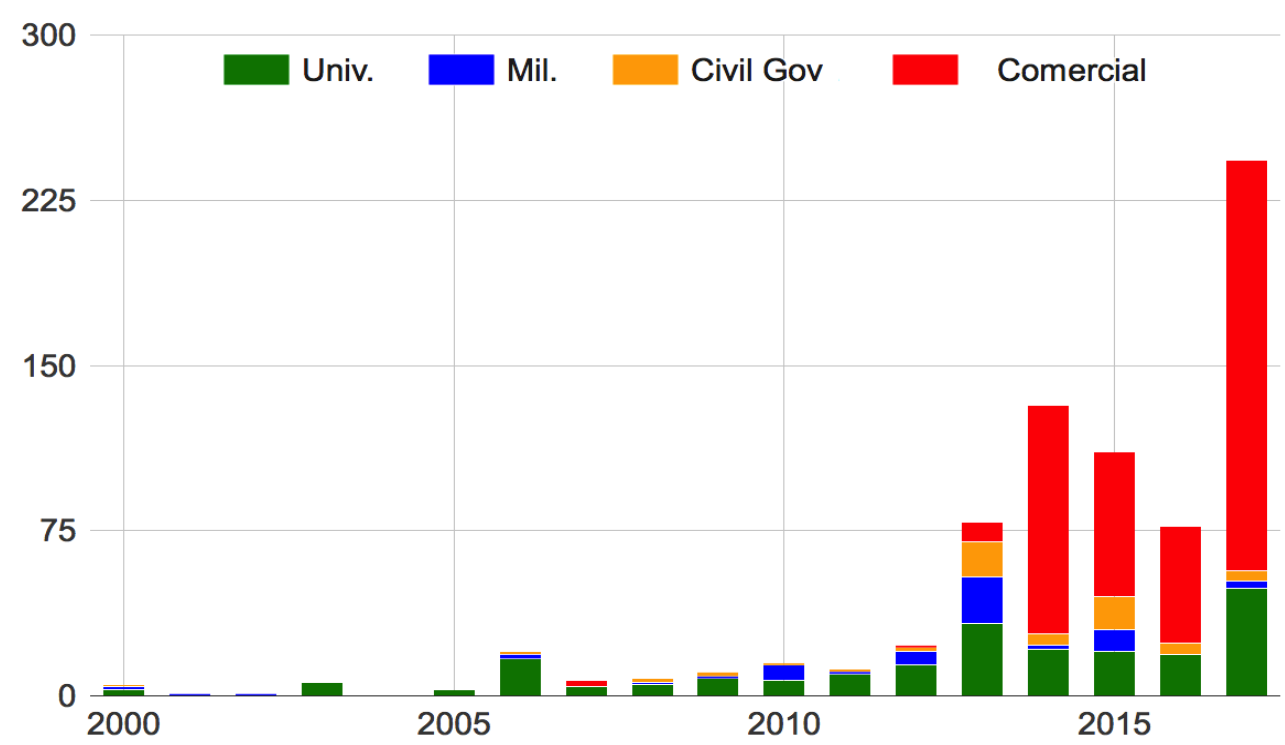

Figura 1: Número de CubeSats por tipo de missão (Univ. - Universidade ou outra instituição educacional, incluindo escolas do ensino médio ou high school; Mil. - Organização governamental militar e/ou de defesa; Civil Gov Organização governamental civil; Comercial - Organização privada) entre 2000 e 2017 (sem constelações). Gráfico gerado on-line com os dados de (Swartwout, 2017).

Os CubeSats geralmente utilizam componentes ditos "comerciais de prateleira" (Commercial Off The Shelf, COTS) ${ }^{2}$ em sua concepção, ao invés de itens com qualificação espacial, caros e difíceis de se obter. Essa solução é uma opção interessante no teste de módulos individuais em desenvolvimento, substituindo a curto prazo, a necessidade de se desenvolver todos os subsistemas do satélite de uma só vez. Essa abordagem foi adotada no projeto CONASAT, priorizando inicialmente, o desenvolvimento de um Receptor/Decodificador para nanossatélites compatível com o SBCDA e com o sistema ARGOS, chamado de Environmental Data Collector (EDC), e do software do Subsistema de Determinação e Controle de Atitude (SDCA).

O projeto CONASAT pretende lançar em breve dois nanossatélites do tipo Cubesat, denominados de CONASAT-0 (padrão 1U) e CONASAT-1 (padrão 2U). Atualmente, o INPE já dispõe de modelos de engenharia (réplicas dos modelos a serem lançados no espaço) que custaram cerca de 200 mil euros, aproximadamente 600 mil reais (na época da aquisição pelo INPE). Os equipamentos em questão foram fabricadas pela empresa holandesa ISIS (Innovation Solutions in Space), uma das líderes mundiais no segmento de CubeSats, representada no Brasil pela Lunus Aeroespacial. A Figura 2 apresenta uma das plataformas (padrão $2 U$ ) já instalada e em fase de testes nos laboratórios do INPE, unidade de Natal.

\footnotetext{
2 Podem existir algumas exceções, como os painéis solares, por exemplo.
} 


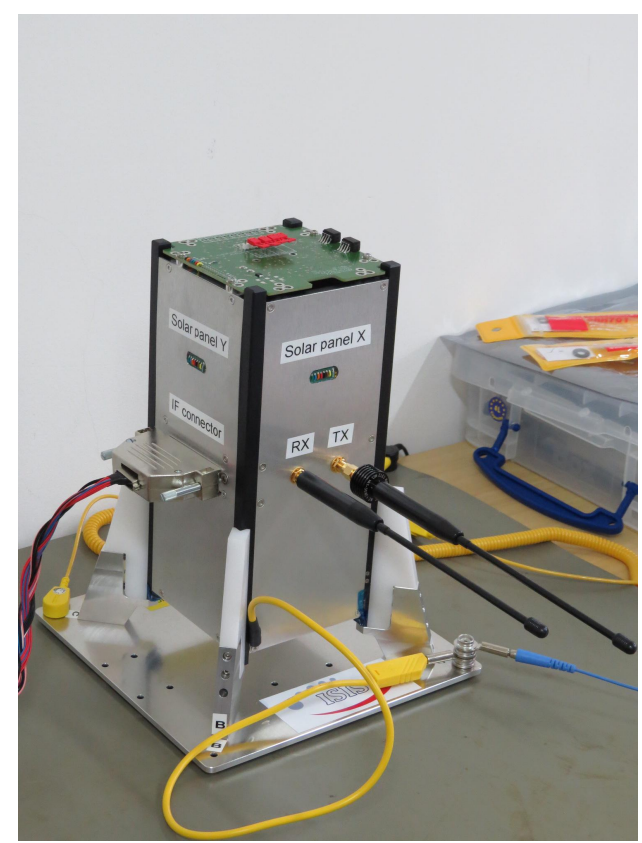

Figura 2: Modelo de engenharia para o nanossatélite CONASAT-1.

O projeto CONASAT também pretende contribuir no desenvolvimento tecnológico da região Nordeste, para que esta possa liderar o surgimento de um novo polo tecnológico, a partir de setores estratégicos associados às áreas de controle, eletrônica e telecomunicações. Além disso, deseja-se capacitar recursos humano para o desenvolvimento de pesquisas e de equipamentos inovadores na área espacial, e também disseminar as tecnologias espaciais na comunidade acadêmica local e entre profissionais interessados no tema.

\section{RECEPTOR/DECODIFICADOR COMPATÍVEL COM O SISTEMA ARGOS}

A solução atual do SBCDA para retransmissão dos sinais das PCDs pelos satélites é um transponder analógico baseado em componentes com qualificação espacial que utiliza uma modulação PM (Phase Modulation) na transmissão. Essa solução, apesar de ser altamente confiável, apresenta algumas características indesejáveis. Dentre elas, podemos citar: o seu modo de operação energeticamente ineficiente, pois opera com um transmissor com modulação analógica; a necessidade de uma visada simultânea entre PCD-satélite e satélite-estação terrestre para a transferência dos dados; o risco de embargo na compra de seus componentes; e por fim, o seu custo, volume e peso elevados.

Dentro desta perspectiva, o desenvolvimento de um receptor/decodificador SBCDA/ARGOS para CubeSat é um passo essencial no sentido de dar continuidade a operação do SBCDA por meio de nanossatélites. A capacidade de decodificar os sinais on-board amplia a cobertura do SBCDA para todo o planeta, pois as mensagens recebidas poderiam ser armazenadas e transmitidas para uma estação receptora num momento oportuno. Outras vantagens são a maior eficiência energética (fundamental em um nanossatélite), e a possibilidade de eliminar um transmissor exclusivo, pois os dados podem ser multiplexados e enviados pelo canal de telemetria do satélite. 
Como um passo intermediário no sentido de obter um decodificador SBCDA para CubeSat baseado em COTS, o projeto CONASAT desenvolveu o Data Collecting System (DCS), uma carga útil para CubeSat funcionalmente idêntica a solução analógica atualmente em operação, porém baseada em COTS e com a modulação PM implementada digitalmente em um FieldProgrammable Gate Array (FPGA). Essa solução foi embarcada como experimento científico no ITASAT-1 (Sato, L. H. S., 2011) (INPE, 2014) e, no momento (13 de Dezembro de 2018), aguarda ser ligada para a realização de testes.

Dando sequência ao desenvolvimento do DCS, iniciou-se o desenvolvimento do EDC, uma solução que já decodifica o sinal das PCDs e disponibiliza as mensagens recebidas para o computador de bordo do satélite. Atualmente, o projeto do EDC se encontrava na etapa de desenvolvimento do Modelo de Engenharia, com um protótipo já tendo sido desenvolvido e aprovado (Duarte, J. 2018).

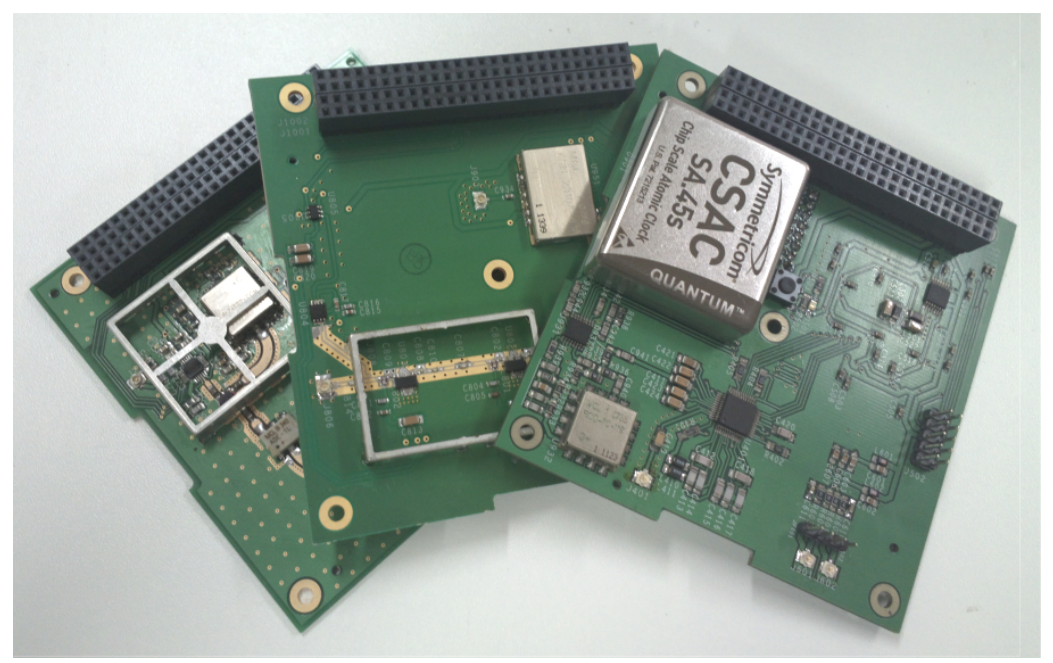

Figura 3: Placas de circuito impresso que compõem o DCS.

A unidade de processamento de sinal e interface de comunicação do EDC é baseada em um SoC (System on a Chip) com FPGA (Field-Programmable Gate Array), em que a parte mais leve do processamento do sinal é realizada em software e a parte mais pesada em hardware. Essa arquitetura, apresentada na Figura 4, é composta pelos seguintes blocos funcionais: ADC ITF (interface com o conversor analógico-digital), RAM (unidade de memória RAM), CTRL (unidade de controle), DEMOD (unidade de demodulação), DETEC (unidade de detecção), BUS ITF (interface de barramento) e MCU (microcontrolador). Inicialmente, a unidade de memória (RAM) armazena as amostras mais recentes do sinal de entrada, que são continuamente fornecidas pelo ADC ITF. Na sequência, o procedimento de detecção do sinal das PCDs é iniciado pelo bloco DETEC, sendo finalizado pelo bloco MCU. A cada 0,01 segundos, o bloco DETEC recebe da RAM uma sequência de amostras do sinal de entrada e realiza as operações mais intensas (em termos computacionais) do processo de detecção. Em seguida, a sua saída é enviada ao bloco MCU através da interface de barramento (BUS ITF). Ao concluir o processo de detecção, o bloco MCU pode ativar novos canais de decodificação, caso novos sinais de PCDs sejam encontrados. Assim como acontece no processo de deteç̧ão, o processo de decodificação é realizado por dois blocos diferentes, o DEMOD e o MCU. O primeiro é responsável pela etapa inicial do processo de 
decodificação (demodulação do sinal). Este procedimento é realizado para todos os canais de decodificação sequencialmente, o que significa que o bloco DEMOD lê uma mesma sequência de amostras de entrada múltiplas vezes, uma vez para cada canal de decodificação ativo. Para limitar os recursos de hardware e memória, o número de canais foi limitado em 12. Já o bloco MCU é responsável por concluir o processo de decodificação, adicionando ainda um cabeçalho (contendo tempo, frequência e potência do sinal) em cada mensagem decodificada. Por fim, o MCU realiza ainda o processo de comunicação entre o DCS e o computador de bordo do satélite (On-Board Computer, OBC). Os sinais de controle para os blocos RAM, DEMOD e DETEC são gerados pelo bloco CTRL.

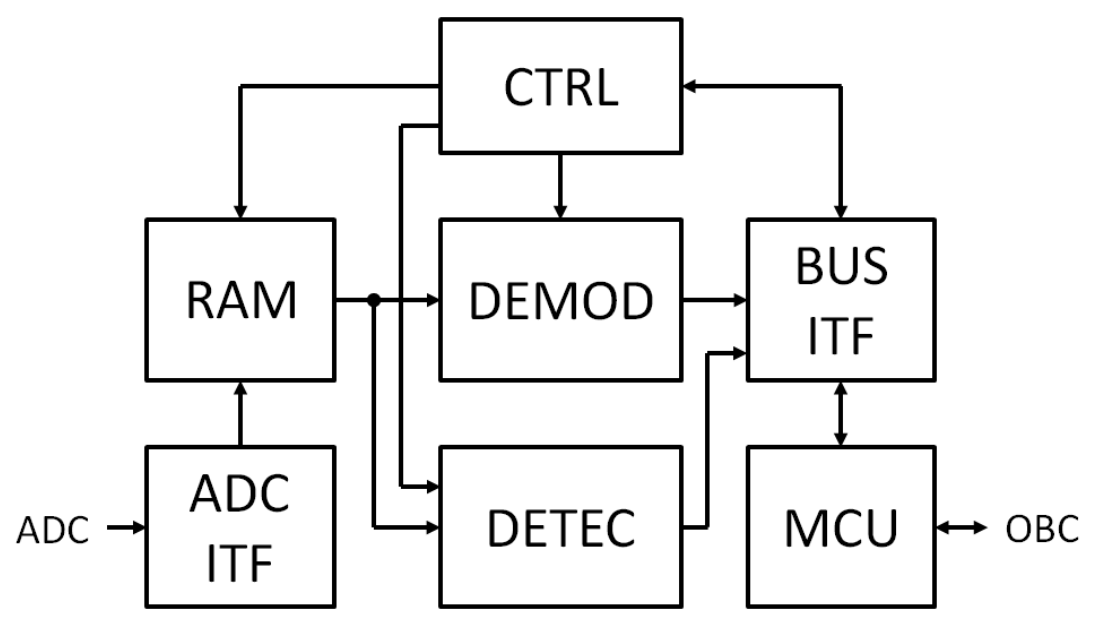

Figura 4: A arquitetura interna do EDC a ser utilizada nos nanossatélites do projeto CONASAT.

O algoritmo de deteç̧ão proposto para o EDC atingiu uma excelente performance, com menos de $2 \%$ de detecção falsa nos testes realizados. Porém, a arquitetura VLSI (Very-Large-Scale Integration) do EDC consumiu muitos elementos lógicos do FPGA. Uma arquitetura VLSI mais otimizada em termos de unidades lógicas já foi considerada, mas novas atualizações e estudos ainda precisam ser elaborados. É interessante ressaltar que o desenvolvimento de um sistema de comunicação para sistemas espaciais possui diversos desafios, como o sincronismo de frequência com a presença de aceleração Doppler e a limitação no consumo de energia. Outro desafio é fazer o sistema robusto a problemas causados pela radiação espacial, como o Single-Event-Upset (SEU) e o Single-Event-Latchup (SEL), que são, respectivamente, corrupção de bits de memória e curto-circuitos corrigíveis.

\section{SOFTWARE DO SUBSISTEMA DE DETERMINAÇÃO E CONTROLE DE ATITUDE (SDCA)}

Considerado como fundamental em diversas missões, o software do Subsistema de Determinação e Controle de Atitude (SDCA) é responsável por determinar a orientação atual do satélite, denominada de atitude, e por direcionar os equipamentos a bordo (antenas e/ou câmeras) em posições específicas da terra ou do espaço. Normalmente, o SDCA apresenta um computador de bordo, sensores do tipo solar e magnético, além de atuadores, como bobinas de torque e/ou rodas de reação. Apesar dos satélites de coleta de dados SCD-1 e SCD-2 serem 
equipados com sensores e atuadores, o processo de determinação e controle de atitude é realizado em tempo real no Centro de Controle de Satélites (CCS), localizado no INPE de São José dos Campos (Winter \& Prado, 2007). Diferente dos seus antecessores, os nanossatélites do projeto CONASAT pretendem realizar a determinação e controle de atitude a bordo, de forma automática e independente, porém informando o resultado desse processo às estações em terra pelo canal de telemetria.

A presença de perturbações no espaço, como o choque entre partículas (lixo espacial, por exemplo) e a estrutura física dos satélites, associada a mudanças do ponto de operação (reposicionamento do satélite), requerem o uso de estratégias de controle mais elaboradas. Dessa forma, um dos objetivos secundários do projeto CONASAT é investigar o uso de estratégias de controle mais robustas, combinando técnicas de estrutura variável e controle adaptativo, no controle de atitude desenvolvido. Neste contexto, serão considerados os trabalhos (Hsu \& Costa, 1989) e (Silva Jr, Araújo, \& Oliveira, 2004), onde o VS-MRAC (Variable Structure Model Reference Adaptive Controller) e o VS-APPC (Variable Structure Adaptive Pole Placement Controller) foram propostos, respectivamente, nas suas versões direta e indireta. A versão indireta do controlador VS-MRAC (IVS-MRAC) foi apresentada em (Oliveira \& Araújo, 2004) cujo projeto do controlador se mostrou mais intuitivo, em virtude da relação entre os parâmetros nominais da planta e a amplitude dos relés. Um controlador em modo dual adaptativo robusto (Dual Mode Adaptive Robust Controller, DMARC) foi ainda proposto em (Cunha, Araújo, \& Mota, 2006) e (Cunha, Araújo, \& Mota, 2007) onde as estratégias MRAC e VS-MRAC são interpoladas com o intuito de incorporar as vantagens de desempenho transitório do VS-MRAC, com as propriedades em regime permanente do MRAC convencional (sinal de controle suave).

Recentemente, um novo cenário com base nos resultados do VS-MRAC foi proposto em (Queiroz \& Araújo, 2008) e estendido em (Queiroz \& Araújo, 2012), para plantas com grau relativo unitário. Denominado de Controlador Adaptativo Backstepping a Estrutura Variável (Variable Structure Adaptive Backstepping Controller, VS-ABC), suas principais características estão relacionadas com um rápido desempenho transitório e robustez na presença de incertezas paramétricas e distúrbios externos.

O diagrama de blocos do software do SDCA é apresentado na Figura 5. Inicialmente, as medidas dos sensores solar e magnético são repassadas ao bloco responsável pela estimação de atitude do nanossatélite (bloco "ESTIMADOR"). Em seguida, com base nos elementos orbitais (parâmetros que definem as características da órbita do satélite), ou na sua versão em TLE (TwoLine Elements), o propagador de órbita (bloco "MODELO ÓRBITA") calcula a posição e velocidade atual do nanossatélite, repassando esses dados ao bloco "MODELO CAMPO MAGNÉTICO". Este último é responsável pelo cálculo das coordenadas do vetor campo magnético em relação a um sistema inercial localizado no centro da terra (Earth-centered Inertial, ECI). Adicionalmente, as coordenadas do vetor direção do sol em relação ao sistema $\mathrm{ECl}$ também são calculadas (bloco "MODELO DIREÇÃO DO SOL") e repassadas ao estimador. Por fim, o bloco "CONTROLE" utiliza as estimativas fornecidas pelo processo de determinação de atitude para gerar os sinais destinados as bobinas de torque (atuadores). 


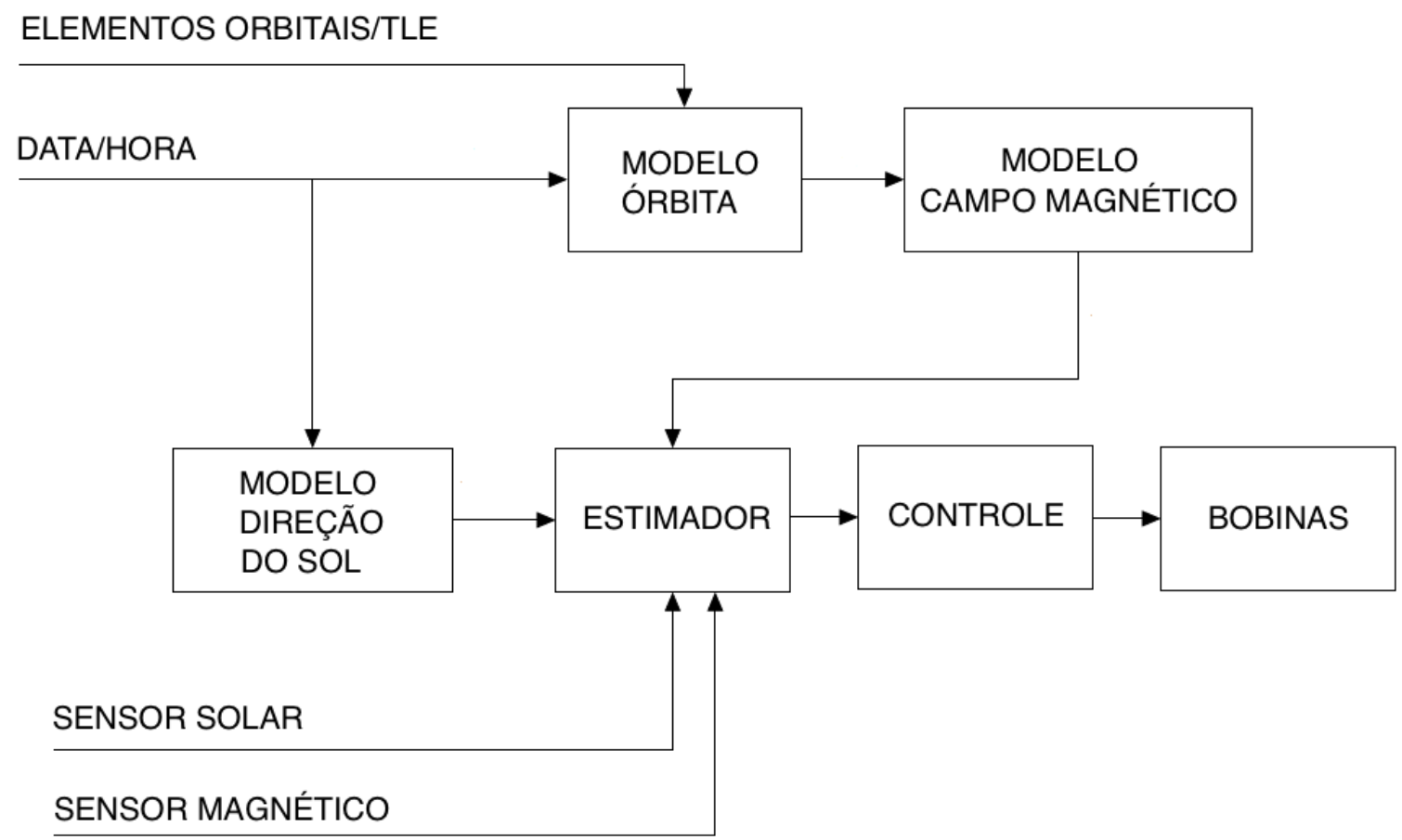

Figura 5: Diagrama de blocos do software do SDCA a ser embarcado nos nanossatélites CONASAT-0 e CONASAT-1.

\section{CONCLUSÃO E CONSIDERAÇÕES FINAIS}

Neste artigo, foi apresentado uma visão geral do projeto CONASAT e de seus principais produtos tecnológicos: o Receptor/Decodificador compatível com o SBCDA e com o sistema ARGOS, chamado de Environmental Data Collector (EDC), e o software do Subsistema de Determinação e Controle de Atitude (SDCA) do satélite. Atualmente, estes produtos estão em fase de testes e em breve estarão disponíveis para serem integrados aos nanossatélites do projeto CONASAT ou em qualquer outro nanossatélite brasileiro. É interessante ressaltar que, segundo o conhecimento dos autores, não existe no país fabricante dessas tecnologias. O projeto CONASAT irá subsidiar o desenvolvimento futuro de um subsistema de controle de atitude completo (hardware e software) e com tecnologia $100 \%$ nacional.

Uma das principais contribuições deste projeto corresponde à redução do custo das missões espaciais com nanossatélites feitas no Brasil, graças à possibilidade de um receptor/decodificador e de um software de determinação e controle de atitude nacional, e como consequência, uma maior acessibilidade desse tipo de missão às universidades, instituições de pesquisa e ao setor privado nacional. Atualmente, as missões de nanossatélites desenvolvidas no Brasil exigem normalmente a compra de todos os subsistemas do satélite (ou a maioria) de empresas estrangeiras. Por fim, a parceria com o INPE vai contribuir para aproximar a UFRN do setor espacial, principalmente no que se refere à formação de recursos humanos nessa área. 


\section{REFERÊNCIAS}

Cunha, C. D., Araújo, A. D., \& Mota, F. C. (2006). A Dual-Mode Adaptive Robust Controller for Plants with Relative Degree One: Stability Analysis. Proceedings of the American Control Conference, Minneapolis, EUA.

Cunha, C. D., Araújo, A. D., \& Mota, F. C. (2007). Controlador em Modo Dual Adaptativo Robusto para Plantas com Grau Relativo Unitário: Prova de Estabilidade, Controle e Automação, 18, 223-233.

Duarte, J. (2018). CubeSat Payload for Environmental Data Collection. Presentations of the United Nations/Brazil Symposium on Basic Space Technology. Natal, Brasil.

Ereno, D. (2014). Pequenos ganham espaço. Recuperado em julho, 2017, de http://revistapesquisa.fapesp.br/2014/05/15/pequenos-ganham-o-espaco/

Hsu, L., \& Costa, R. R. (1989). Variable Structure Model Reference Adaptive Control Using Only Input and Output Measurements - Part I, International Journal of Control, 49, 399-416.

INPE (2014). [Online]. INPE desenvolve novo transponder para satélites de coleta de dados ambientais. Notícia institucional do INPE. Recuperado em 14/12/2018 de http://www.inpe.br/noticias/noticia.php?Cod_Noticia=3810

Oliveira, J. B., \& Araújo, A. D. (2004). An Indirect Variable Structure Model Reference Adaptive Control Applied to the Speed Control of a Three-Phase Induction Motor. Proceedings of the American Control Conference, Boston, EUA.

Queiroz, K., \& Araújo, A. D. (2008). A proposal for a variable structure adaptive backstepping control. Proceedings of the IEEE International Workshop on Variable Structure Systems, Antalya, Turquia.

Queiroz, K., Araújo, A. D., \& Dias, S. (2012). Design and stability analysis of a variable structure adaptive backstepping controller, Asian Journal of Control, 14(3), 641-651.

Sato, L. H. S., Yamaguti, W. \& Fernandes, D. (2011). ITASAT-1: uma proposta de continuidade do Sistema Brasileiro de Coleta de Dados Ambientais. Anais XV Simpósio Brasileiro de Sensoriamento Remoto - SBSR, Curitiba, PR, Brasil.

Silva Jr, F. C., Araújo, A. D., \& Oliveira, J. B. (2004). A Proposal for a Variable Structure Adaptive Pole Placement Control. Proceedings of the IEEE International Workshop on Variable Structure Systems, Vilanova, Espanha.

Sousa, F. L. de (2007). Desenvolvimento de satélites e plataformas espaciais no INPE no período 1961-2007. Recuperado em fevereiro, 2016, de http://www.inpe.br/twiki/pub/Main/IntroducaoTecnologiaSatelitesDesenvolvimento_Satelit es.pdf

Swartwout, M. CubeSats Data Base [Online]. Recuperado em 16 de agosto, 2017, de https://sites.google.com/a/slu.edu/swartwout/home/cubesat-database/census

Winter, O. C., \& Prado, A. F. B. de A. (Orgs.). (2007). A Conquista do Espaço: do Sputnik à Missão Centenário. São Paulo: Livraria Da Física. 